\title{
Application of the Champion Health Belief Model to determine beliefs and behaviors of Turkish women academicians regarding breast cancer screening: A cross sectional descriptive study
}

\author{
Nukhet Kirag ${ }^{1 *}$ (D) and Mehtap KızIlkaya²
}

\begin{abstract}
Background: Breast cancer is an important cancer type and the most common malignancy among women in both developed and developing countries and the second leading cause of cancer death in women worldwide. This study aimed to examine the projected risk of breast cancer in Turkish women academician, determine the levels of their breast cancer screening behaviors and uncover the relationship between their health beliefs and screening behaviors.

Methods: This cross-sectional descriptive study was conducted from March to July 2018 in the province of Aydın, Turkey with a total of 200 female academicians. The data were collected using questionnaires filled out by the participants and the Turkish version of the Champion Health Belief Model Scale. Data were analyzed using t test, ANOVA, Chi-square and logistic regression performed with Statistical Package for Social Sciences version 20.

Results: The mean age of the female academics was $36.1 \pm 0.53$ years. The female performing breast selfexamination had higher perceived sensitivity $(\mathrm{OR}=2.88,95 \% \mathrm{Cl} 1.32,2.66)$ benefits to breast self-examination $(\mathrm{OR}=$ $0.90,95 \% \mathrm{Cl} 0.82,0.99)$, self-efficacy $(\mathrm{OR}=0.87,95 \% \mathrm{Cl} 0.81,0.93)$ health motivation $(\mathrm{OR}=1.74,95 \% \mathrm{Cl} 0.50,0.90)$, benefit to mammography $(\mathrm{OR}=0.97,95 \% \mathrm{Cl} 0.88,1.08)$, lower barrier to mammography $(\mathrm{OR}=1.05,95 \% \mathrm{Cl} 1.0,1.09)$ than women who did not. Female academics with clinical breast examination had higher self-efficacy $(\mathrm{OR}=0.91$, $95 \% \mathrm{Cl} 0.86,0.97)$ and lower barrier to mammography $(\mathrm{OR}=1.06,95 \% \mathrm{Cl} 1.02,1.10)$ than women who did not. The female with take mammography had higher sensitivity $(\mathrm{OR}=0.84,95 \% \mathrm{Cl} 0.72,0.98)$, lower barrier to breast selfexamination $(\mathrm{OR}=1.08,95 \% \mathrm{Cl} 1.02,1.15)$ and lower barrier to mammography $(\mathrm{OR}=1.09,95 \% \mathrm{Cl} 1.04,1.14)$ than female who did not.

Conclusions: Female academicians in Turkey exhibit positive attitudes towards breast self-examination, clinical breast examination and mammography as they have higher perceived sensitivity against breast cancer, self-efficacy and fewer barriers. Long-term community-based programs should be extended to different groups of women from a variety of socio-demographic environments.
\end{abstract}

Keywords: Breast cancer, Health belief model, Screening, Barriers, Turkish academicians

\footnotetext{
* Correspondence: nukhetkirag@gmail.com

${ }^{1}$ Public Health Nursing Department, Aydın Adnan Menderes University

Faculty of Nursing, Kepez Mevkii, 09010 Efeler/Aydın, Turkey

Full list of author information is available at the end of the article
}

(c) The Author(s). 2019 Open Access This article is distributed under the terms of the Creative Commons Attribution 4.0 International License (http://creativecommons.org/licenses/by/4.0/) which permits unrestricted use, distribution, and reproduction in any medium, provided you give appropriate credit to the original author(s) and the source, provide a link to the Creative Commons license, and indicate if changes were made. The Creative Commons Public Domain Dedication waiver (http://creativecommons.org/publicdomain/zero/1.0/) applies to the data made available in this article, unless otherwise stated. 


\section{Background}

Breast cancer $(\mathrm{BC})$ is an important cancer type and the most common malignancy among women in both developed and developing countries [1], and the second leading cause of cancer death in women worldwide [2]. It accounts for $30-40 \%$ of all the cancers in women all over the world [3]. Among adolescent and young women, BC ranks as the most frequently diagnosed invasive cancer, and represents approximately $25 \%$ of $\mathrm{BC}$ cases diagnosed among all women in the United States [4]. In addition, young women diagnosed with $\mathrm{BC}$ have a worse clinical course than older women. The incidence of $\mathrm{BC}$ in young women also varies by race, with young black women having a much higher incidence compared with white women in the same age group [5]. The incidence rate of $\mathrm{BC}$ is also increasing rapidly in Turkey, 45.1 in 100,000 women [6].

Even though the incidence of $\mathrm{BC}$ has increased, the death rate has fallen due to early diagnosis and effective treatment [7]. Although the American Cancer Society no longer recommends that all women perform monthly breast self-exams (BSE), all women should become familiar with both the appearance and feel of their breasts and report any changes promptly to their physician [7]. American Cancer Society recommends that women should undergo regular screening mammography starting at age 45 years [7].

Mammography, clinical breast examination (CBE) and $\mathrm{BSE}$ are recommended for the early diagnosis of $\mathrm{BC}$ [6]. In Turkey, national society-based $\mathrm{BC}$ screening is performed by the Family Health Centers (FHC), Cancer Early Diagnosis, Screening and Education Centers (CEDSEC) oversight by the Social Health Centers (SHC). Although the main screening method is mammography, CBE is also performed for every woman who is screened in order to increase the efficiency of mammography. Furthermore, a consultancy service must be offered to every woman over 20 years of age to enable them to perform BSE on their own, to create awareness in the society [6]. According to the national screening standards for breast cancer in Turkey, BSE must be performed once a month over the age of 20; CBE must be performed once in 2 years over the age of 20 and once a year over the age of 40; and mammography must be performed once in 2 years between the ages 40 and 69 [6].

Beliefs have powerful effects on lifestyles. The Champion health belief model is a psychosocial model that is intended to explain health behaviors and to determine the factors that affect women's BC beliefs and screening behaviors. According to this model, health behavior, which is the integration of individual perceptions and values directing people to certain ends, is directly related to the development of diseases [8]. Education and health beliefs are critical in the early diagnosis of $\mathrm{BC}$ in developing countries where the number of female university graduates is lower [8]. Previous studies have shown that most Turkish women do not carry out regular BC screening behaviors in practice [8-10]. New policies regarding $\mathrm{BC}$ are constantly being developed in Turkey, which is also considered as a developing country. Thus, one of the goals of the Turkey Cancer Control Plan 20132018 is to increase BSE and mammography in asymptomatic women for early diagnosis [11].

The major function of a university is research, education and public service. It is widely accepted that academicians play an effective role in creating health behaviors. Academicians transfer information and interact with a large part of the population [12]. Female academicians are role models for other woman to protect social rights of women, to lead healthier lives and to assume responsibility for their own health. Academicians as are in a position to inform young people about BC risk factors, types of screening practices and thus affect their behaviors in a way that will reduce the risk of $\mathrm{BC}$ and mortality rates [12]. However, studies carried out with female academicians regarding this issue are limited [12-14].

The specific aims of this study were to examine the projected risk of $\mathrm{BC}$ in female Turkish academicians, determine the levels of their $\mathrm{BC}$ screening behaviors and uncover the relationship between their health beliefs and screening behaviors. We also report the findings from backgrounds and educations of these women both in and outside health areas. The results would reveal if the women with education in health would practice, what they preach.

\section{Methods}

\section{Study design and sampling}

This cross-sectional descriptive study was carried out from March to July 2018 with female academicians in Aydın (Aydın Adnan Menderes University), Turkey. The study population was determined to be 156 with the Gpower program using an impact size of $0.40, \alpha=0.05$ and power $(1-\beta)=0.80$ at a confidence level of $95 \%$. Their schools were divided into two groups: health care schools and other schools. The number of female academicians from each school was determined using stratified sampling followed by simple random sampling. The following formula was used to determine the sample size.

n: Sample size,

$\mathrm{N}$ : Number of units in the population,

Nh: number of units in layer $h$,

$\mathrm{Sh}^{2}$ : variance of layer $\mathrm{h}, \mathrm{D}^{2}=\left(\mathrm{d}^{2} / \mathrm{z}^{2}\right)$,

$\mathrm{d}$ : The maximum error amount that can be accepted by the investigator or the difference between the sample mean and the population mean, 
$\mathrm{z}$ : This is the $\mathrm{z}$ value in the standard normal distribution table according to the margin of error.

$$
\frac{\mathrm{N} \cdot \sum\left(\mathrm{Nh} \cdot \mathrm{Sh}^{2}\right) \mathrm{n}=}{\mathrm{N}^{2} \cdot \mathrm{D}^{2}+\sum\left(\mathrm{Nh} \cdot \mathrm{Sh}^{2}\right)}
$$

A total of 200 female academicians were included in the study. Of them, 135 were in the health care field, and 65 were in other fields.

The inclusion criteria were: Women academician, working in Aydın Adnan Menderes University, agreed to participate in the study.

\section{Data collection and ethics}

This study was approved by the Aydın Adnan Menderes University Faculty of Health Sciences Ethics Committee [code number:2018/08]. Permission to carry out the study was obtained from the Rectorate of Adnan Menderes University before the data collection. A validated and reliable self-administered, structured questionnaire was prepared according to the Health Belief Model Scale for BC Screening, developed by Champion 1984 and the validity and reliability of Turkish version as tested by Gozum and Aydin, together with an extensive review of the literature on sociodemographic forms $[15,16]$. After obtaining the participants' written and verbal consent to participate, the study's purpose and its benefits for women's health were briefly explained. Academicians included in the study were visited in their schools and all the participants filled out the forms by their own in approximately $15 \mathrm{~min}$.

\section{Socio-demographic characteristics questionnaire}

The questionnaire was developed for this study. And the questionnaire hasn't been published elsewhere. This questionnaire included 20 questions about the participants' age, marital status, school field, title, family type, income level, smoking, drinking alcohol, exercise level, chronic disease, mental illness, giving birth, BC screening in the last 6 months, regular BSE, BC history of close relatives, body type, stress control levels, health assessment, eating habits and sleep habits. In addition, the questions "Have you ever done any BSE?" and "Can you perform a regular BSE?" were asked to determine the practice of BSE, with the response options of "yes" or "no", "Can you mark your sleep habits" was asked to select one of the given expressions to "I would lay out at the same time as the regular time and be careful to sleep at the same time as the previous day", "Some nights I only sleep for a few hours, except that I regularly sleep", "My sleep order does not change every day", "Do you have a chronic disease?", with the response options of "yes", "no".

\section{The Champion health belief model scale for breast Cancer} screening

This scale has been developed by Champion in 1984 and revised in 1993,1997 and lastly in 1999 for the health beliefs concerning BSE and mammography screening of $\mathrm{BC}$, and it was translated into Turkish by a number of researchers and culturally adapted for use with the Turkish population $[15,16]$. This study used the Turkish version of CHBMS developed by Gözüm and Aydın (2004). This particular version includes 52 Likert-type items in six subscales: perceived sensitivity, perceived severity, and benefits of BSE, BSE barriers, self-efficacy and health motivation. The participants were asked to rate each item on a five-point scale: 1 , I strongly disagree; 2, I disagree; 3, I am undecided; 4, I agree, and 5, I strongly agree. The highest scores on each subscale are: 3-15 for perceived sensitivity, 6-30 for perceived severity, 4-20 for benefits of BSE, 8-40 for BSE barriers, 10-50 for self-efficacy and 5-25 for health motivation. High scores indicate more positive opinions and attitudes towards health for all the subscales except the subscale of BSE barriers, where higher scores indicate more barriers [16]. The Cronbach's alpha values were: 0.89 for sensitivity, 0.85 for severity, 0.80 for health motivation, 0.86 for BSE benefits, 0.81 for BSE barriers, 0.91 for BSE self-efficacy, 0.73 for mammography benefits and 0.88 for mammography barriers. Permission to use this scale was obtained.

\section{Data analysis}

Data were analyzed using t-test, One-way ANOVA, and Chi-square tests using Statistical Package for Social Sciences (SPSS) version 20.The threshold for statistical significance was $p<0.05$. This study used percentages, means and standard deviation values as descriptive statistics. In order to determine the preliminary indicators of BSE, CBE and mammography logistic regression was performed with the factors that were found to be statistically significant in bivariate analysis. This analysis used performing and not performing BSE as dependent variables, and age, title, birth, academic field, BSE training, chronic disease and income level as independent variables. Its results determined relative risk (odds ratio, $\mathrm{OR}$ ) at a $95 \%$ confidence interval (CI). The retraction method (Wald) was used as the regression model.

\section{Results}

The response rate was $100 \%$ among participants. The mean age of the female academicians was $36.1 \pm 0.53$ years (minimum:23-maximum:60) and $51.5 \%$ were between the ages of 30 and 40 . Of the participants, 57\% were married, $67.5 \%$ were working in health field and $29.5 \%$ were assistant professors. Of them, $90 \%$ had nuclear families, $54.5 \%$ had more income than expenses, 
and $73 \%$ were non-smokers. Among female academicians, $52.5 \%$ did not take alcohol, $60 \%$ exercised sometimes, $20 \%$ had a chronic disease, and $13 \%$ had a mental illness. Of the participants, $7 \%$ had a family history of BC and 51.5\% had given birth. Sixty-seven (33.5\%) female academicians reported that they had been screened for BC in the last 6 months. Eighty-three (41.5\%) female academicians reported that they performed BSE regularly on a monthly basis. Ninety-seven (48.5\%) female academicians said that they have at least one CBE. Sixty seven (33.5\%) participants expressed that they have performed at least one mammography. More than $50 \%$ of the participants said that they were in good health, $53.5 \%$ said they had normal eating habits, and $49.5 \%$ said they had regular sleep habits (Table 1).

Table 2 shows the participants' scores on each subscale of the CHBMS: sensitivity, $7.7 \pm 2.1$; seriousness, $19.3 \pm 5.1$; benefits of BSE, $15.1 \pm 3.3$; barriers to BSE, $16.0 \pm 5.3$; self-efficacy, $22.0 \pm 5.5$; health motivation, $20.5 \pm 2.6$; benefits of mammography, $17.0 \pm 3.3$, and barriers to mammography, $22.6 \pm 8.1$ (Table 2). Evaluation of the mean scores for different groups and CHBMS subscales shown in Table 2 found that participants between the ages of 30 and 40 had higher scores in the area of perceived BSE barriers, that participants who were under 30 years old had higher scores in the area of perceived mammography barriers and that participants over the age of 41 had higher perceived self-efficacy scores. The analysis found that there was a significant difference within the subscale of sensitivity and school of employment and chronic disease. Table 2 shows significant associations between BSE barriers and income level, sleep habits, regular BSE and at least one BSE. There were some significant differences in income level, sleep habits, BC screening in the last 6 months, BSE training, at least one BSE, regular BSE and at least one CBE. There were relationships between the subscale of selfefficacy and income level, sleep habits, breast cancer screening in the last 6 months, BSE training, at least one BSE, regular BSE and at least one CBE. A relationship existed between the subscale of mammography benefits and income level. The low-income participants' scores were significantly higher than those of the other income levels $(p<0.05)$. The subscale of mammography barrier scores of those who had not been screened for $\mathrm{BC}$ in the last 6 months and those who never had a $\mathrm{CBE}$ were significantly higher than those who had. There was a significant association between the subscale of barriers to BSE and barriers to mammography. The women who had mammograms had fewer perceived BSE and mammography barriers than those who did not have.

The characteristics of the group that was performing BSE and the group that was not were compared statistically. Table 3 shows significant associations between
BSE and age, title, giving birth, $\mathrm{BC}$ screening in the last 6 months, BSE training, chronic disease and mental illness $(p<0.05)$. Working area (health or not) and family history of BC were not related with BSE (Table 3).

Tables 4 presents adjusted ORs for each subscale performing $\mathrm{BSE}, \mathrm{CBE}$, and mammography using logistic regression. Female academicians performing BSE had higher perceived sensitivity $(\mathrm{OR}=2.88,95 \% \mathrm{Cl} 1.32$, 2.66), benefits to BSE (OR $=0.90,95 \% \mathrm{Cl} 0.82,0.99)$, self efficacy $(\mathrm{OR}=0.87,95 \% \mathrm{Cl} 0.81,0.93)$, health motivation $(\mathrm{OR}=1.74,95 \% \mathrm{Cl} 0.50,0.90)$, and benefit to mammography $(\mathrm{OR}=0.97,95 \% \mathrm{Cl} 0.88,1.08)$ compared to academicians who did not perform BSE. In addition, participants who perform BSE had lower barrier to mammography $(\mathrm{OR}=1.05,95 \% \mathrm{Cl} 1.0,1.09)$ than those who did not. Participants who had CBE reported higher self efficacy (OR = $0.91,95 \% \mathrm{Cl} 0.86,0.97)$ and lower barrier to mammography $(\mathrm{OR}=1.06,95 \% \mathrm{Cl} 1.02,1.10)$ than women who did not. Academicians who performed mammography had higher sensitivity ( $\mathrm{OR}=0.84,95 \% \mathrm{Cl} 0.72,0.98)$, lower barrier to BSE $(\mathrm{OR}=1.08,95 \% \mathrm{Cl} 1.02,1.15)$, and lower barrier to mammography $(\mathrm{OR}=1.09,95 \% \mathrm{Cl} 1.04,1.14)$ than those who did not (Table 4).'

\section{Discussion}

Our findings show that the practices of BSE, CBE and mammography were $41.5,48.5$ and $33.5 \%$, respectively. This rate has ranged from 27.1 to $42.7 \%$ in previous Turkish studies [8-14]. However, these studies have shown that women in Turkey perform BSE at less than the desired level. Iranian women [17], Malaysian women [18], Qatari women [19], Saudi women [20] and Indian women [21] also have similarly low prevalence of screening for the early detection of $\mathrm{BC}$. The results from these countries being close to those of Turkey may be due to similar socio-economic and cultural factors. Cultural factors, modesty and the use of Eastern medicine were shown to be significantly correlated with Korean-American women's health beliefs and cancer screening behaviors [22].

The percentage of academicians in this study who perform monthly BSE (41.5\%) was much higher than the previous Turkish studies conducted with academicians [11-14]. Yllmaz et al. (2011) found that female academicians did the recommended $\mathrm{BC}$ screening tests such as BSE, CBE and mammography more than housewives [14]. These results suggested that the educational level has a positive effect on performing BSEs. Ekici and Utkualp (2007) reported that $20.9 \%$ academician women performed BSE [23]. Ceber et al. (2009) also found that $27.7 \%$ of female academicians performed regular BSE [24]. The most important factor in female academicians' high frequency of BSE performance may be related to education levels and lower BSE barriers. Previous studies of the factors that affect screening behavior have 
Table 1 Sociodemographic variables and lifestyle behaviors of academicians

\begin{tabular}{|c|c|c|}
\hline Variables & Number & Percent \\
\hline$\overline{\text { Age }(\text { Mean } \pm \text { SD) }}$ & & $36.1 \pm 0.53$ \\
\hline Under 30 & 45 & 22.5 \\
\hline $30-40$ & 103 & 51.5 \\
\hline 41 and above & 52 & 26 \\
\hline \multicolumn{3}{|l|}{ Marital status } \\
\hline Married & 114 & 57 \\
\hline Single & 72 & 36 \\
\hline Divorced & 14 & 7 \\
\hline \multicolumn{3}{|l|}{ School } \\
\hline Health field & 135 & 67.5 \\
\hline Outside the health area & 65 & 32.5 \\
\hline \multicolumn{3}{|l|}{ Title } \\
\hline Research assistant & 73 & 36.5 \\
\hline Lecturer & 43 & 21.5 \\
\hline Assistant Professor & 59 & 29.5 \\
\hline Associate Professor & 18 & 9 \\
\hline Professor & 6 & 3 \\
\hline \multicolumn{3}{|l|}{ Family Type } \\
\hline Nuclear family & 180 & 90 \\
\hline Extended family & 16 & 8 \\
\hline Single parent family & 4 & 2 \\
\hline \multicolumn{3}{|l|}{ Income level } \\
\hline More than expenses & 109 & 54.5 \\
\hline Equal to expenses & 85 & 42.5 \\
\hline Less than expenses & 6 & 3 \\
\hline \multicolumn{3}{|l|}{ Active Smoking } \\
\hline Yes & 54 & 27 \\
\hline No & 146 & 73 \\
\hline \multicolumn{3}{|l|}{ Current Alcohol intake } \\
\hline Yes & 95 & 47.5 \\
\hline No & 105 & 52.5 \\
\hline
\end{tabular}

Exercise

Regular 17

Sometimes $\quad 120$

No

63

Chronic Disease

Yes

No

Mental ilness

Yes

No

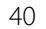

160
Table 1 Sociodemographic variables and lifestyle behaviors of academicians (Continued)

\begin{tabular}{cll}
\hline Variables & Number & Percent \\
\hline No & 97 & 48.5
\end{tabular}

$\mathrm{BC}$ screening in the last 6 months (BSE/CBE/Mammography)

$\begin{array}{lll}\text { Yes } & 67 & 33.5 \\ \text { No } & 133 & 66.5\end{array}$

Regular performance of BSE

No

No $83 \quad 41.5$

$117-58.5$

Have you ever had a CBE?

$\begin{array}{lll}\text { Yes } & 97 & 48.5\end{array}$

$\begin{array}{lll}\text { No } & 103 & 51.5\end{array}$

Have you ever taken mammography?

$\begin{array}{lll}\text { Yes } & 67 & 33.5\end{array}$

$\begin{array}{lll}\text { No } & 133\end{array}$

History of BC in first-degree relatives

$\begin{array}{lll}\text { Yes } & 14 & 7\end{array}$

$\begin{array}{lll}\text { No } & 186 & 93\end{array}$

Body type

Slim $\quad 53 \quad 26.5$

Normal $\quad 124 \quad 62$

$\begin{array}{lll}\text { Overweight } & 23 & 11.5\end{array}$

Stress control

I get angry $\quad 48 \quad 24$

I control my stress $\quad 128$

I ignore stress $\quad 24 \quad 12$

Health assessment

Very good 26

Good $106 \quad 13$

Normal $\quad 65 \quad 53$

$\begin{array}{lll}\text { Poor } & 3 & 32.5\end{array}$

Eating habit $\quad 1.5$

Normal 107

Junk food $\quad 77 \quad 53.5$

Abnormal $\quad 16 \quad 38.5$

Sleeping habit 8

$\begin{array}{lll}\text { Regular } & 99 & \\ \text { Some nights a few hours } & 64 & 49.5 \\ \text { Irregular } & 37 & 32 \\ & & 18.5 \\ \text { Total } & 200 & 100\end{array}$

${ }^{\circ} B C$ Breast Cancer, BSE Breast Self Examination, CBE Clinical Breast Examination

identified these barriers: lack of information, fear and worries [20], fear of a cancer diagnosis, cost, lack of free time, forgetfulness and embarrassment [19]. Regular BSE 
Table 2 Health beliefs scale of breast cancer screening assessment in women academician

\begin{tabular}{|c|c|c|c|c|c|c|c|c|}
\hline \multirow{2}{*}{$\begin{array}{l}\text { Risk factors } \\
\text { Age (years) }\end{array}$} & \multicolumn{8}{|c|}{ Health beliefs scale of BC screening } \\
\hline & Sensitivity & Seriousness & Motivation & $\begin{array}{l}\text { BSE } \\
\text { (benefits) }\end{array}$ & $\begin{array}{l}\text { BSE } \\
\text { (barriers) }\end{array}$ & $\begin{array}{l}\text { Self } \\
\text { efficacy }\end{array}$ & $\begin{array}{l}\text { Mammography } \\
\text { (benefits) }\end{array}$ & $\begin{array}{l}\text { Mammography } \\
\text { (barriers) }\end{array}$ \\
\hline Under 30 & $7.2 \pm 2.4$ & $19.4 \pm 5.5$ & $19.6 \pm 3.2$ & $15.0 \pm 3.1$ & $16.6 \pm 4.7$ & $21.9 \pm 5.2$ & $16.9 \pm 2.4$ & $24.0 \pm 8.3$ \\
\hline $30-40$ & $7.8 \pm 1.9$ & $19.4 \pm 5.0$ & $20.8 \pm 2.4$ & $14.9 \pm 3.5$ & $16.8 \pm 5.6$ & $21.1 \pm 5.7$ & $17.0 \pm 3.3$ & $23.8 \pm 8.2$ \\
\hline 41 and above & $7.8 \pm 2.3$ & $19.1 \pm 4.8$ & $20.8 \pm 2.5$ & $15.6 \pm 2.9$ & $13.7 \pm 4.8$ & $23.6 \pm 4.8$ & $17.3 \pm 4.1$ & $18.9 \pm 6.5$ \\
\hline$P$ value & .298 & .944 & .053 & .544 & ${ }^{*} .002$ & ${ }^{*} .026$ & .822 & ${ }^{*} .001$ \\
\hline \multicolumn{9}{|l|}{ School } \\
\hline Health field & $7.3 \pm 2.3$ & $19.0 \pm 5.5$ & $21.1 \pm 2.2$ & $15.6 \pm 3.0$ & $16.0 \pm 4.3$ & $23.5 \pm 3.9$ & $17.1 \pm 3.3$ & $21.6 \pm 7.4$ \\
\hline $\begin{array}{l}\text { Outside the health } \\
\text { area }\end{array}$ & $8.0 \pm 1.7$ & $18.7 \pm 4.2$ & $20.7 \pm 2.2$ & $15.3 \pm 3.4$ & $16.7 \pm 6.2$ & $20.0 \pm 5.2$ & $16.5 \pm 2.5$ & $24.7 \pm 8.3$ \\
\hline$P$ value & ${ }^{*} .008$ & .078 & .326 & .835 & .456 & ${ }^{*} .000$ & .420 & .935 \\
\hline \multicolumn{9}{|l|}{ Title } \\
\hline Lecturer & $7.8 \pm 2.08$ & $19.6 \pm 5.0$ & $20.3 \pm 2.8$ & $15.1 \pm 3.0$ & $16.9 \pm 4.8$ & $21.6 \pm 5.4$ & $17.1 \pm 2.9$ & $23.9 \pm 8.3$ \\
\hline Associate & $7.4 \pm 2.2$ & $18.9 \pm 5.2$ & $20.9 \pm 2.3$ & $15.0 \pm 3.7$ & $14.7 \pm 5.8$ & $22.6 \pm 5.6$ & $16.9 \pm 3.9$ & $20.7 \pm 7.5$ \\
\hline$P$ value & .068 & .584 & .066 & .613 & ${ }^{*} .019$ & .325 & .057 & .051 \\
\hline \multicolumn{9}{|l|}{ Income level } \\
\hline More than expenses & $7.8 \pm 2.4$ & $19.6 \pm 5.5$ & $20.7 \pm 2.4$ & $15.4 \pm 2.7$ & $15.7 \pm 5.2$ & $23.0 \pm 4.4$ & $17.6 \pm 2.8$ & $21.8 \pm 8.4$ \\
\hline Equal to expenses & $7.5 \pm 1.7$ & $19.2 \pm 4.6$ & $20.5 \pm 2.5$ & $15.1 \pm 3.0$ & $17.1 \pm 4.9$ & $21.2 \pm 5.2$ & $16.0 \pm 3.9$ & $23.7 \pm 7.6$ \\
\hline Less than expenses & $8.5 \pm 1.6$ & $16.1 \pm 3.6$ & $18.1 \pm 7.3$ & $8.6 \pm 8.4$ & $8.3 \pm 6.5$ & $\begin{array}{l}11.8 \pm \\
13.0\end{array}$ & $19.0 \pm 1.0$ & $28.5 \pm 5.3$ \\
\hline$P$ value & .577 & .260 & .080 & ${ }^{*} .000$ & ${ }^{*} .000$ & ${ }^{*} .000$ & ${ }^{*} .002$ & ${ }^{*} .064$ \\
\hline \multicolumn{9}{|l|}{ Chronic Disease } \\
\hline Yes & $8.8 \pm 1.7$ & $19.6 \pm 5.0$ & $20.5 \pm 2.7$ & $15.2 \pm 2.6$ & $15.5 \pm 5.6$ & $22.4 \pm 5.2$ & $15.8 \pm 3.7$ & $23.9 \pm 7.4$ \\
\hline No & $7.4 \pm 2.1$ & $19.3 \pm 5.1$ & $20.5 \pm 2.6$ & $15.0 \pm 3.5$ & $16.1 \pm 5.3$ & $21.9 \pm 5.5$ & $17.4 \pm 3.2$ & $22.2 \pm 8.2$ \\
\hline$P$ value & ${ }^{*} .000$ & .753 & .892 & .118 & .658 & .894 & .580 & .415 \\
\hline \multicolumn{9}{|l|}{ Sleeping habit } \\
\hline Regular & $7.5 \pm 1.9$ & $19.1 \pm 4.7$ & $20.6 \pm 2.5$ & $15.1 \pm 3.4$ & $15.1 \pm 5.0$ & $20.6 \pm 5.9$ & $16.8 \pm 3.1$ & $22.9 \pm 8.1$ \\
\hline $\begin{array}{l}\text { Some nights a few } \\
\text { hours }\end{array}$ & $8.0 \pm 2.1$ & $19.6 \pm 5.1$ & $20.5 \pm 2.9$ & $15.2 \pm 3.2$ & $17.5 \pm 5.7$ & $22.6 \pm 4.4$ & $17.3 \pm 3.1$ & $22.6 \pm 8.7$ \\
\hline Irregular & $7.6 \pm 2.5$ & $19.5 \pm 5.7$ & $20.1 \pm 2.5$ & $14.6 \pm 3.4$ & $15.7 \pm 5.0$ & $24.0 \pm 4.9$ & $16.9 \pm 4.1$ & $21.9 \pm 7.1$ \\
\hline$P$ value & .398 & .785 & .681 & .722 & ${ }^{*} .016$ & ${ }^{*} .003$ & .686 & .825 \\
\hline \multicolumn{9}{|c|}{$\mathrm{BC}$ screening in the last 6 months } \\
\hline Yes & $8.2 \pm 2.0$ & $18.3 \pm 5.2$ & $20.7 \pm 2.4$ & $15.7 \pm 2.6$ & $14.6 \pm 4.6$ & $23.3 \pm 3.9$ & $17.4 \pm 3.3$ & $19.5 \pm 6.4$ \\
\hline No & $7.4 \pm 2.2$ & $19.9 \pm 5.0$ & $20.5 \pm 2.8$ & $14.7 \pm 3.6$ & $16.7 \pm 5.6$ & $21.2 \pm 6.0$ & $16.8 \pm 3.4$ & $24.1 \pm 8.5$ \\
\hline$P$ value & .279 & 698 & .164 & ${ }^{*} .009$ & .199 & ${ }^{*} .021$ & .453 & ${ }^{*} .042$ \\
\hline \multicolumn{9}{|l|}{ BSE training } \\
\hline Yes & $7.7 \pm 2.2$ & $18.8 \pm 5.1$ & $20.6 \pm 2.5$ & $15.6 \pm 2.8$ & $15.1 \pm 4.8$ & $23.6 \pm 3.8$ & $17.5 \pm 2.9$ & $20.7 \pm 7.2$ \\
\hline No & $7.5 \pm 2.1$ & $20.3 \pm 4.8$ & $20.3 \pm 2.9$ & $14.1 \pm 3.9$ & $17.6 \pm 5.9$ & $18.7 \pm 6.7$ & $16.2 \pm 4.0$ & $26.2 \pm 8.6$ \\
\hline$P$ value & .459 & .283 & .688 & ${ }^{*} .035$ & .724 & ${ }^{*} .000$ & .151 & .523 \\
\hline \multicolumn{9}{|c|}{ Have you ever done BSE? } \\
\hline Yes & $7.5 \pm 2.1$ & $19.0 \pm 5.0$ & $20.7 \pm 2.7$ & $15.3 \pm 3.5$ & $15.1 \pm 5.1$ & $22.8 \pm 5.1$ & $17.1 \pm 3.6$ & $21.9 \pm 8.2$ \\
\hline No & $8.2 \pm 2.0$ & $20.4 \pm 5.4$ & $20.0 \pm 2.3$ & $14.1 \pm 2.4$ & $19.3 \pm 4.9$ & $18.9 \pm 5.7$ & $16.7 \pm 2.0$ & $25.3 \pm 7.0$ \\
\hline$P$ value & .351 & .882 & .273 & .467 & ${ }^{*} .000$ & ${ }^{*} .000$ & ${ }^{*} .019$ & .227 \\
\hline \multicolumn{9}{|l|}{ Does it regularly BSE? } \\
\hline Yes & $8.1 \pm 2.0$ & $18.7 \pm 4.9$ & $20.8 \pm 2.4$ & $15.7 \pm 2.8$ & $14.1 \pm 5.1$ & $23.4 \pm 4.7$ & $16.7 \pm 3.9$ & $21.2 \pm 7.9$ \\
\hline No & $7.4 \pm 2.1$ & $19.8 \pm 5.1$ & $20.3 \pm 2.8$ & $14.6 \pm 3.5$ & $17.3 \pm 5.1$ & $20.9 \pm 5.8$ & $17.2 \pm 2.9$ & $23.5 \pm 8.1$ \\
\hline
\end{tabular}


Table 2 Health beliefs scale of breast cancer screening assessment in women academician (Continued)

\begin{tabular}{|c|c|c|c|c|c|c|c|c|}
\hline \multirow{2}{*}{$\begin{array}{l}\text { Risk factors } \\
\text { Age (years) }\end{array}$} & \multicolumn{8}{|c|}{ Health beliefs scale of BC screening } \\
\hline & Sensitivity & Seriousness & Motivation & $\begin{array}{l}\text { BSE } \\
\text { (benefits) }\end{array}$ & $\begin{array}{l}\text { BSE } \\
\text { (barriers) }\end{array}$ & $\begin{array}{l}\text { Self } \\
\text { efficacy }\end{array}$ & $\begin{array}{l}\text { Mammography } \\
\text { (benefits) }\end{array}$ & $\begin{array}{l}\text { Mammography } \\
\text { (barriers) }\end{array}$ \\
\hline$P$ value & .888 & .877 & .532 & ${ }^{*} .036$ & .515 & .100 & .138 & .601 \\
\hline \multicolumn{9}{|c|}{ Were there any CBE? } \\
\hline Yes & $7.8 \pm 2.4$ & $19.0 \pm 5.2$ & $20.9 \pm 2.1$ & $15.5 \pm 2.8$ & $15.2 \pm 5.1$ & $23.3 \pm 4.6$ & $17.0 \pm 3.8$ & $20.6 \pm 7.5$ \\
\hline No & $7.6 \pm 1.9$ & $19.6 \pm 5.0$ & $20.2 \pm 3.1$ & $14.7 \pm 3.7$ & $16.7 \pm 5.5$ & $20.7 \pm 5.9$ & $17.0 \pm 2.8$ & $24.2 \pm 7.9$ \\
\hline$P$ value & .463 & .376 & .152 & .051 & .605 & ${ }^{*} .001$ & .939 & ${ }^{*} .001$ \\
\hline \multicolumn{9}{|c|}{ Were there any taken mammography? } \\
\hline Yes & $8.05 \pm 2.2$ & $18.8 \pm 5.26$ & $20.6 \pm 2.5$ & $15.2 \pm 2.9$ & $14.5 \pm 5.3$ & $23.0 \pm 4.6$ & $17.3 \pm 3.8$ & $19.3 \pm 6.8$ \\
\hline No & $7.53 \pm 2.1$ & $19.6 \pm 5.04$ & $20.5 \pm 2.7$ & $15.0 \pm 3.5$ & $16.7 \pm 5.2$ & $21.4 \pm 5.8$ & $16.9 \pm 3.1$ & $24.3 \pm 8.2$ \\
\hline$P$ value & .306 & .336 & .263 & .268 & .006 & .050 & .072 & .000 \\
\hline
\end{tabular}

${ }^{\bar{B}} B C$ Breast Cancer, BSE Breast Self Examination, CBE Clinical Breast Examination

$p$ value is below 0.05

Table 3 Association analysis between variables and performing BSE $(n=200)$

\begin{tabular}{|c|c|c|c|c|c|}
\hline \multirow[t]{2}{*}{ Characteristics } & \multicolumn{2}{|c|}{$\begin{array}{l}\text { Performing BSE } \\
(N=83)\end{array}$} & \multicolumn{2}{|c|}{$\begin{array}{l}\text { Not performing BSE } \\
(N=117)\end{array}$} & \multirow[t]{2}{*}{ Statisitcs } \\
\hline & $n$ & $\%$ & $n$ & $\%$ & \\
\hline \multicolumn{6}{|l|}{ Age (years) } \\
\hline Under 30 & 11 & 13.3 & 34 & 29.1 & \multirow{3}{*}{$\begin{array}{l}X^{2}=2.546 \\
P=0.000\end{array}$} \\
\hline $30-40$ & 37 & 44.5 & 66 & 56.4 & \\
\hline 41 and above & 35 & 42.2 & 17 & 14.5 & \\
\hline \multicolumn{6}{|l|}{ Title } \\
\hline Lecturer & 36 & 43.4 & 80 & 69 & \multirow{2}{*}{$\begin{array}{l}X^{2}=13.03 \\
P=0.000\end{array}$} \\
\hline Associate & 47 & 56.6 & 36 & 31 & \\
\hline \multicolumn{6}{|l|}{ Giving Birth } \\
\hline Yes & 53 & 63.9 & 50 & 42.7 & \multirow{2}{*}{$\begin{array}{l}X^{2}=8.671 \\
P=0.003\end{array}$} \\
\hline No & 30 & 36.1 & 67 & 57.3 & \\
\hline \multicolumn{6}{|c|}{$\mathrm{BC}$ screening in the last 6 months } \\
\hline Yes & 51 & 61.4 & 16 & 13.9 & \multirow{2}{*}{$\begin{array}{l}X^{2}=48.65 \\
P=0.000\end{array}$} \\
\hline No & 32 & 38.6 & 99 & 86.1 & \\
\hline \multicolumn{6}{|l|}{ School } \\
\hline Health field & 26 & 63.4 & 34 & 51.5 & \multirow{2}{*}{$\begin{array}{l}X^{2}=1.45 \\
P=0.228\end{array}$} \\
\hline Outside the health area & 15 & 36.6 & 32 & 48.5 & \\
\hline \multicolumn{6}{|l|}{ BSE training } \\
\hline Yes & 69 & 83.1 & 63 & 53.8 & \multirow{2}{*}{$\begin{array}{l}X^{2}=18.55 \\
P=0.000\end{array}$} \\
\hline No & 14 & 16.9 & 54 & 46.2 & \\
\hline \multicolumn{6}{|l|}{ Chronic Disease } \\
\hline Yes & 25 & 30.1 & 15 & 12.8 & \multirow{2}{*}{$\begin{array}{l}X^{2}=9.62 \\
P=0.008\end{array}$} \\
\hline No & 58 & 69.9 & 102 & 87.2 & \\
\hline \multicolumn{6}{|c|}{ History of $\mathrm{BC}$ in first-degree relatives } \\
\hline Yes & 3 & 23.1 & 10 & 76.9 & $X^{2}=3.35$ \\
\hline No & 80 & 42.9 & 105 & 57.1 & $P=0.186$ \\
\hline
\end{tabular}

* $B C$ Breast Cancer, BSE Breast Self Examination, $C B E$ Clinical Breast Examination $p$ value is below 0.05 
Table 4 Logistic regression analysis of health belief model subscales for performing breast cancer screening

\begin{tabular}{|c|c|c|c|c|c|c|}
\hline \multirow[t]{2}{*}{ Variable } & \multicolumn{2}{|l|}{ BSE } & \multicolumn{2}{|l|}{$\mathrm{CBE}$} & \multicolumn{2}{|l|}{ Mammography } \\
\hline & $\mathrm{OR}(95 \% \mathrm{Cl})$ & $\mathrm{p}$ & $\mathrm{OR}(95 \% \mathrm{Cl})$ & $p$ & $\mathrm{OR}(95 \% \mathrm{Cl})$ & $p$ \\
\hline Sensitivity & $2.88(1.32,2.66)$ & .000 & $0.90(0.78,1.04)$ & .182 & $0.84(0.72,0.98) .030$ & \\
\hline Seriousness & $1.05(0.98,1.13)$ & .113 & $1.01(0.95,1.08)$ & .571 & $1.02(0.96,1.09)$ & .445 \\
\hline Barriers to BSE & $1.19(1.10,1.29)$ & .000 & $1.04(0.98,1.10)$ & .140 & $1.08(1.02,1.15)$ & .008 \\
\hline Benefits to BSE & $0.90(0.82,0.99)$ & .041 & $1.00(0.90,1.11)$ & .946 & $1.03(0.92,1.15)$ & .557 \\
\hline Self efficiacy & $0.87(0.81,0.93)$ & .000 & $0.91(0.86,0.97)$ & .008 & $0.94(0.88,1.00)$ & .074 \\
\hline Health motivation & $1.74(0.50,0.90)$ & .000 & $0.93(0.83,1.05)$ & .305 & $1.02(0.91,1.15)$ & .695 \\
\hline Barriers to mammography & $1.05(1.0,1.09)$ & .021 & $1.06(1.02,1.10)$ & .001 & $1.09(1.04,1.14)$ & .000 \\
\hline Benefits to mammography & $0.97(0.88,1.08)$ & .694 & $1.02(0.93,1.12)$ & .558 & $0.98(0.90,1.08)$ & .779 \\
\hline
\end{tabular}

${ }^{*} B C$ Breast Cancer, BSE Breast Self Examination, $C B E$ Clinical Breast Examination $p$ value is below 0.05

ranged for Nigerian women to $54.8 \%$ [25] for Indian women to $26 \%$ [26] for Iranian women to $14.9 \%$ and overall $10.6 \%$ of women aged $21-53$ years had received mammogram [27], while this percentage was much higher than the mammography practice of $51.5 \%$ in our study. Whereas, studies conducted in similar populations, the rate of undergoing mammography ranged from 5.1 to $25 \%[5,9,11-14]$.

OR (Odds ratio) showed that positive attitude on the sensitivity, self efficacy, health motivation, benefit to BSE scales significantly all increased BSE performance. Sensitivity scale significantly increased mammography practice. Self efficacy scale significantly increased CBE performance. Less barriers lead more likely to the practice of BSE, CBE and mammography. Hence, by using the CHBMS construct, the health care provider can understand the beliefs that may affect the women's BSE, $\mathrm{CBE}$ and mammography practices. Higher scores on all scales except for the barriers indicate positive attitude, as expected screening behavior, while for barriers, a higher score indicates negative attitude. In this study, perceived seriousness was not significantly associated with BSE, CBE and mammography practice. Similarly, in other studies on Turkish women, seriousness has been reported to be a nonsignificant predictor of $\mathrm{BSE}, \mathrm{CBE}$ and mammography $[8,9,14]$.

Our study found correlations between mean CHBMS subscale scores and age, school, income levels, chronic disease, sleep habits, BC screening behaviors, BSE training, performing BSE and CBE behavior. The literature includes few studies with which to compare these findings. Similarly, Demirkan et al. (2011) found that the age and profession affect BSE performance [28]. Fouladi et al. (2013) determined that there is a negative relationship between age and mammography barriers and a direct relationship between age and perceived sensitivity [29]. The current results are similar to those of Fouladi (2013). However, Dündar et al. found that age and educational levels did not affect CHBMS subscale scores
[30]. Likewise, Altunkan et al. found that age did not affect women's CHBMS subscale scores [31].

It is important to demonstrate that the perceived benefits of early diagnosis behavior are greater than the perceived barriers [32]. Low perceived barriers and high perceived benefits are important factors in women's early diagnosis behavior. The results of logistic regression analysis found four CHBMS variables with significant risk ranges (sensitivity, BSE barriers, self-efficacy, and mammography benefits). This study determined that the women who did BSE had higher perceived sensitivity, fewer perceived barriers and higher self-efficacy than the women who did not. Similarly to this finding, Ceber et al. (2009), Çam and Gümüş (2009) and Yılmaz et al. (2011) also reported that women with high self-efficacy carry out BSE more frequently than women with low self-efficacy [14, 24, 32]. Female academicians' high selfefficacy and health motivation may be related to their educational and social status in the population.

This study found, like previous studies, that female academicians who do BSE have lower perceived barriers [11-14]. Turkish academicians had less perceived barriers and higher self-efficacy levels [13]. Jordanian women had limited knowledge regarding $\mathrm{BC}$ despite the national efforts to promote public awareness about $\mathrm{BC}$ and screening methods [33]. This difference may be due to the fact that academicians in Turkish universities are better trained and more informed about BSE practice than Jordanian women or due to cultural differences [33]. In some studies, sensitivity, severity, motivation and benefits were not found to be related to performing BSE $[15,32]$, but in others, these variables were found to be important preliminary indicators of BSE [13, 32].

It is surprising that there was no difference between the academicians in the field of health and academicians in other fields concerning CHBMS scores and BSE, CBE and mammography. However, individuals who have received health education and specialized in this subject are expected to have higher awareness, motivation, self- 
efficacy and benefit perceptions about BC screening behaviors and low perceptions about the barriers. It was thought that the similarity of the variables such as education and profession could have an impact on such outcome. In this article, the sociodemographic characteristics of female academicians with high educational level and the relationship between chbm scale and subscales were examined in detail.

The fact that this is a cross-sectional study and not including the longitudinal monitoring of the participants constitute its limitations. The data were collected by self-reporting. Since the frequency of BSE, CBE and mammography are based on subjective memories; the participants may have made mistakes in remembering the past history. The study's sample consisted of female academicians and thus it cannot be generalized to the wider population of Turkey.

\section{Conclusion}

Female academicians in Turkey exhibit positive attitudes towards BSE, CBE and mammography as they have higher perceived sensitivity against $\mathrm{BC}$, self-efficacy and fewer barriers. But there are still more room for progress. Also, women in health disciplines appear as not practicing what they preach. Further minimizing the barriers towards the screening behaviors can effectively persuade the academician women. Interventions should focus more on the practical implementations. Data on the health beliefs can be used to determine the critical factors that affect $\mathrm{BC}$. Improved health education and implementation of critical strategies should further enhance the performance of BC screening. Long-term community-based programs should be extended to different groups of women from a variety of socio-demographic environments.

\section{Abbreviations}

BC: Breast cancer; BSE: Breast self examination; CBE: Clinical breast examination; CHBMS: Champion Health Belief Model Scale

\section{Acknowledgements}

The researchers would like to thank the University for allowing them to conduct the study. The authors are grateful to the Deanship of Faculties at Aydin Adnan Menderes University. Special thanks also to the academician women who participated, for their time, honesty and effor.

\section{Authors' contributions}

NK performed study design and analyzed the data. MK performed collection the data and was a contributor in writing the manuscript. All authors read and approved the final manuscript.

\section{Funding}

No funding

\section{Availability of data and materials}

The data sets used and analyzed during the current study are available from the corresponding author on reasonable request.

\section{Ethics approval and consent to participate}

Approval to conduct the study was obtained from the Aydin Adnan Menderes University Faculty of Health Science ethics committee (2018/08).
Participation in the study was voluntary and nameless in order to guarantee confidentiality. After obtaining the participants' written and verbal consent to participate, the study's purpose and its benefits for women's health were briefly explained.

\section{Consent for publication}

The participants consented for the study to be published but assured of anonymity before administering the questionnaire. The participants were also given the opportunity to ask questions about the study at any stage, and to withdraw from the study at any time.

\section{Competing interests}

The authors declare that they have no competing interests.

\section{Author details}

${ }^{1}$ Public Health Nursing Department, Aydın Adnan Menderes University Faculty of Nursing, Kepez Mevkii, 09010 Efeler/Aydın, Turkey. ${ }^{2}$ Psychiatric Nursing Department, Aydın Adnan Menderes University Faculty of Nursing, Kepez Mevkii, 09010 Efeler/Aydın, Turkey.

Received: 20 March 2019 Accepted: 10 October 2019

Published online: 06 November 2019

\section{References}

1. Hajian T, Karimollah SA. Health belief model and practice of breast selfexamination and breast cancer screening in Iranian women. Breast Cancer. 2014;21:429-34.

2. Boulos DNK, Ghali RR. Awareness of breast cancer among female students at Ain Shams University, Egypt. Global J Health Sci. 2014;6:154-61.

3. Che CC, Coomarasamy J, Suppayah DB. Perception of breast health among Malaysian female adolescents. APJCP. 2014;15:7175-80.

4. Ademuyiwa FO, Gao F, Hao L, Morgensztern D, Aft RL, Ma CX, et al. US breast cancer mortality trends in young women according to race. Cancer. 2015:121:1469-76.

5. Reeder-Hayes KE, Meyer AM, Dusetzina S, Liu H, Wheeler SB. Racial disparities in initiation of adjuvant endocrine therapy of early breast cancer. Breast Cancer Res Treat. 2014;145:743-51.

6. Republic of Turkey Ministry of Health, 2015. https://hsgm.saglik.gov.tr/ depo/birimler/kanser-db/istatistik/Turkiye_Kanser_Istatistikleri_2015.pdf. Accessed 5 Oct 2017

7. Smith RA, Andrews KS, Brooks D, Fedewa SA, Manassaram-Baptiste D, Saslow D, et al. Cancer screening in the United States, 2018: a review of current American Cancer Society guidelines and current issues in cancer screening. CA Cancer J Clin. 2018;68:297-316.

8. Avci IA, Kumcagiz H, Altinel B, Caloglu A. Turkish female academician self-esteem and health beliefs for breast cancer screening. APJCP. 2014:15:155-60.

9. Gençtürk N, Demirezen E, Ay F. Health beliefs of midwifery students at Istanbul University about breast cancer and breast self-examination acknowledgements. J Cancer Educ. 2017;32:784-9.

10. Karadag G, Gungormus Z, Surucu R, Savas E, Bicer F. Awareness and practices regarding breast and cervical cancer among Turkish women in Gaziantep. APJCP. 2014;15:1093-8.

11. Açıkgöz A, Çehreli R, Ellidokuz H. Determination of knowledge and behavior of women working at a hospital on breast cancer early detection methods, and investigation of efficiency of planned education. J Breast Health. 2015;11:31.

12. Duman NB, Algier $L$, Pinar $G$. Health beliefs of the female academicians about breast cancer, screening tests and the affecting factors. Int I Hematol Oncol. 2013;27:233-41.

13. Ceber E, Yücel U, Mermer G, Ozentürk G. Health beliefs and breast selfexamination in a sample of Turkish women academicians in a university. APJCP. 2009:10:213-8

14. Yilmaz M, Guler G, Bekar M, Guler N. Risk of breast cancer, health beliefs and screening behaviour among Turkish academic women and housewives. APJCP. 2011;12:817-22.

15. Champion VL. Instrument development for health belief model constructs. Adv Nurs Sci. 1984;6:73-85.

16. Gözüm S, Aydin I. Validation evidence for Turkish adaptation of Champion's health belief model scales. Cancer Nurs. 2004;27:491-8. 
17. Montazeri A, Vahdaninia M, Harirchi I, Harirchi AM, Sajadian A, Khaleghi F, et al. Breast cancer in Iran: need for greater women awareness of warning signs and effective screening methods. Asia Pac Fam Med. 2008;7:6.

18. Parsa P, Kandiah M, Zulkefli NM, Rahman HA. Knowledge and behavior regarding breast cancer screening among female teachers in Selangor. Malaysia APJCP. 2008;9:221-8

19. Bener A, El Ayoubi HR, Moore MA, Basha B, Joseph S, Chouchane L. Do we need to maximise the breast cancer screening awareness? Experience with an endogamous society with high fertility. APJCP. 2009;10:599-604.

20. Amin TT, Al Mulhim AR, Al MA. Breast cancer knowledge, risk factors and screening among adult Saudi women in a primary health care setting. APJCP. 2009;10:133-8.

21. Khokhar A. Breast cancer in India: where do we stand and where do we go? APJCP. 2012;13:4861-6.

22. Eun Y, Lee EE, Kim MJ, Fogg L. Breast cancer screening beliefs among older Korean American women. J Gerontol Nurs. 2009;35:40-50.

23. Ekici $\mathrm{E}$, Utkualp N. Female teaching staff attitudes towards breast cancer. J Breast Hlth. 2007:3136-9.

24. Ceber E, Turk M, Ciceklioglu M. The effects of an educational program on knowledge of breast cancer, early detection practices and health beliefs of nurses and midwives. J Clin Nurs. 2010;19:2363-71.

25. Ogunbode AM, Fatiregun AA, Ogunbode OO. Breast self examination practices in Nigerian women attending a tertiary outpatient clinic. Indian J Cancer. 2015:52:520-4.

26. Kumarasamy H, Veerakumar AM, Subhathra S, Suga Y, Murugaraj R. Determinants of awareness and practice of breast self examination among rural women in Trichy, Tamil Nadu. J Midlife Health. 2017;8:84.

27. Shiryazdi SM, Kholasehzadeh G, Neamatzadeh H, Kargar S. Health beliefs and breast cancer screening behaviors among Iranian female health workers. APJCP. 2014;15:9817-22.

28. Demirkiran F, Ozgun H, Eskin M, Turk G, Cam R, Ozgun O, et al. Cognition of breast cancer among gestational age Turkish women: a cross-sectional study. APJCP. 2011;12:277-82.

29. Fouladi N, Pourfarzi F, Mazaheri E, Aslı HA, Rezaie M, Amani F, et al. Beliefs and behaviors of breast cancer screening in women referring to health care centers in Northwest Iran according to the champion health belief model scale. APJCP. 2013:14:6857-62.

30. Dündar PE, Özmen D, Öztürk B, Haspolat G, Akyıldız F, Çoban S, et al. The knowledge and attitudes of breast self-examination and mammography in a group of women in a rural area in western Turkey. BMC Cancer. 2006;6:43.

31. Altunkan $H, A k ı n ~ B, E g e ~ E$. Awareness and practice of breast self examination (BSE) among 20-60 years women. J Breast Health. 2008;4:84-91.

32. Çam $\mathrm{O}$, Gümüs AB. Breast cancer screening behavior in Turkish women: relationships with health beliefs and self-esteem, body perception and hopelessness. APJCP. 2009;10:49-56.

33. Othman A, Ahram M, Al-Tarawneh MR, Shahrouri M. Knowledge, attitudes and practices of breast cancer screening among women in Jordan. Health Care Women Int. 2015;36:578-92.

\section{Publisher's Note}

Springer Nature remains neutral with regard to jurisdictional claims in published maps and institutional affiliations.

Ready to submit your research? Choose BMC and benefit from:

- fast, convenient online submission

- thorough peer review by experienced researchers in your field

- rapid publication on acceptance

- support for research data, including large and complex data types

- gold Open Access which fosters wider collaboration and increased citations

- maximum visibility for your research: over $100 \mathrm{M}$ website views per year

At $\mathrm{BMC}$, research is always in progress.

Learn more biomedcentral.com/submissions 